\title{
Ensino e Amazônia: a anÁlise da música "Belém- PARÁ-BRAsil" No DESVElamento dA COLONIALIDAde COMO CRÍTICA SOCIOAMBIENTAL
}

\author{
TEACHING AND THE AMAZON: THE ANALYSIS OF THE MUSIC "BELÉM- \\ PARÁ-BRASIL" IN THE UNVEILING OF COLONIALITY AS A SOCIO- \\ ENVIRONMENTAL CRITIC
}

DOI: 10.23926/RPD.2526-2149.2020.v5.n3.p2069-2087.id810

\section{Ivone dos Santos Siqueira \\ Doutoranda em Educação em Ciências, (IEMCI/UFPA) \\ Técnica em Assuntos \\ Educacionais no Instituto \\ Federal do Pará (IFPA) \\ ivone.siqueiraifpa@gmail.co \\ $\underline{\mathrm{m}}$}

\section{Michelly da Silva \\ Fernandes}

Graduanda em Licenciatura

Integrada em Ciências,

Matemática e Linguagens

(UFPA)

michellyfernandes100@hot

mail.com

\section{Elinete Oliveira \\ Raposo}

Doutora em Educação em

Ciências

Professora da Universidade

Federal do Pará

(IEMCI/UFPA)

elineterr@gmail.com

\section{Nadia Magalhães da \\ Silva Freitas \\ Doutora em \\ Desenvolvimento \\ Sustentável do Trópico \\ Úmido (UFPA) \\ Professora do Instituto de \\ Educação Matemática e \\ Científica (IEMCI/UFPA) \\ nadiamsf@yahoo.com.br}

Resumo: O artigo trata da análise da música "Belém-Pará-Brasil", da Banda Mosaico de Ravena, composta por Edmar da Rocha, com o objetivo de trazer possibilidades à discussão socioambiental crítica no âmbito escolar, precisamente no desvelamento das "marcas" da colonialidade presentes na referida canção. Recorremos à análise de conteúdo, de base temática, para desvelamento dessas marcas. A canção, aqui tida como objeto de estudo, apresenta um "desabafo" na forma de crítica socioambiental aos eventos que ainda insistem em ocorrer na Amazônia. Basicamente três categorias analíticas são apresentadas: aquelas que tratam da ocupação da Amazônia, invisibilidade dos amazônidas e o discurso desenvolvimentista, estereótipos criados sobre a Amazônia e os amazônidas e influência das culturas alienígenas na Amazônia. Tais aspectos constituem-se resultados da dominação colonial, ainda hoje presente enquanto processo de colonialismo continuado. A música em questão, quando da sua utilização em sala de aula, pode se constituir prática decolonial, com potencial pedagógico para a construção de uma outra visão da Amazônia, diferente do olhar eurocêntrico.

Palavras-chave: Decolonialidade. Amazônia. Ensino. Música.

\begin{abstract}
This study discusses the "marks" of coloniality present in the song "Belém-Pará-Brasil", by the Band Mosaico de Ravena, composed by Edmar da Rocha, with the objective of bringing possibilities to the critical social-environmental discussion in the school environment, precisely on the unveiling of the "marks" of coloniality present in this song. We used thematic analysis of content to unveil these marks. The song, here considered as an object of study, presents an outburst in the form of socio-environmental criticism to the events that still insist happen in the Amazon. Basically three analytical categories are presented: those dealing with occupation of the Amazon, invisibility of the amazonian populations and the discourse developmental, the stereotypes created about the Amazon region and the amazonian populations and, finally, the incorporation of alien cultures by the inhabitants of the region. Such aspects are the result of colonial domination, still present in the region. The music in question, when used in the classroom, can be a decolonial practice, with pedagogical potential for the construction of another vision of the Amazon, different from the Eurocentric view.
\end{abstract}

Keywords: Decoloniality. Amazon. Teaching. Music. 


\section{INTRODUÇÃO}

A Amazônia, no quadro de eventos contemporâneos, vinculado à sua exploração social e ambiental, constitui-se objeto de conhecimento por excelência. Seu estudo compreende considerar diferentes domínios temáticos do conhecimento, tratando-se, portanto, de um tema que adentra ao campo interdisciplinar. Em geral, a Amazônia é tida como um espaço de grande sociobiodiversidade (VIEIRA; TOLEDO; HIGUCHI, 2018). Isso, entretanto, não tem impedido a construção de visões que a consideram como natureza intocada, vazio demográfico, reserva de recurso, questão nacional, além de região periférica, entre outras (PORTOGONÇALVES, 2019).

Esses conteúdos e contextos precisam ser problematizados à luz da perspectiva decolonial, de modo a melhor entendermos os cenários construídos (e em construção) para/na Amazônia, cuja maior preocupação remete, sobremaneira, para o campo socioambiental, em face da crescente exploração degenerativa em nome do capital, para que não sejamos “instrumentalizados” a favor deste estado de coisa. É nesse contexto, que a educação, em geral, e o ensino de ciências, em particular, necessita envidar esforços para a adoção de práticas decoloniais no espaço de sala de aula, entendida como um "[...] conjunto de práticas e discursos que desconstroem a narrativa colonial como foi escrita pelo colonizador, e tenta substituí-la por narrativas escritas do ponto de vista do colonizado" (SANTOS, 2002, p. 13).

Na mesma linha, podemos afirmar que as práticas decoloniais buscam suscitar reflexões para a compreensão dos métodos hegemônicos de subordinação e de subalternização. Assim, o desenvolvimento de práticas decoloniais procura levar os sujeitos aprendentes à percepção ampliada das estratégias que buscam legitimar a dominação. Uma ação é decolonial quando ela contesta a colonialidade do poder e são estas ações que podem transformar a realidade (PEIXOTO; FIGUEIREDO, 2018).

Porto-Gonçalves (2015) ressalta a necessidade de analisar a região amazônica, tendo em vista as relações sociais e políticas a partir das relações de poder. Para Oliveira (2018, p. 356),

A Região Amazônica sempre foi pensada por meio do olhar eurocêntrico. Seu
processo de colonização e a tentativa de dominação dos povos indígenas que aqui
moravam, partem de uma perspectiva civilizatória europeia. Mas não é somente pelo
europeu que essa região foi(é) colonizada. Vista como periferia do Brasil, a Amazônia
ainda é pouco compreendida por boa parte dos brasileiros. Pensa-se em um lugar com
muitos recursos naturais infinitos, ou um lugar que deve ser, exclusivamente,
explorado por quem é de fora, visto que sua população local não seria capaz de lidar
com essas riquezas. Além disso, boa parte das políticas públicas discutidas para a
região parecem ignorar que nela vivem ribeirinhos, camponeses, remanescentes de
quilombos e indígenas e acabam não levando em consideração que cada um tem suas 
especificidades, suas necessidades e uma percepção única com a natureza que os cerca.

A perspectiva decolonial, aqui considerada, pode contribuir para a construção de uma outra visão da Amazônia, diferente do olhar eurocêntrico, nos seguintes termos:

[...] para se entender a Amazônia é preciso construir uma nova visão, tal como Chico Mendes propusera, de buscar uma sociedade que tenha outras relações sociais e de poder que apontem para a justiça e a igualdade entre os homens e mulheres, sobretudo convivendo com a radicalidade da democracia e onde a natureza não seja recurso, ou um meio ao serviço de um fim. Enfim, não só novas relações sociais e de poder entre os homens e mulheres, mas também novas relações com a natureza[...] (PORTOGONÇALVES, 2015, p. 85).

As discussões sobre as questões socioambientais amazônicas, enquanto práticas decoloniais, constituem processos de formação ambiental, ao compreenderem práticas pedagógicas ideológicas e conceituais “[...] para produção e aquisição de conhecimentos e saberes, num processo histórico de transformação social" (LEFF, 2008, p. 254).

Desse modo, propomo-nos, neste artigo, a elaborar uma análise crítica do conteúdo da canção "Belém-Pará-Brasil"1, à luz das perspectivas decoloniais, para refletir sobre a Amazônia, tendo como bases teóricas para análise os autores Porto-Gonçalves, Gilberto de Souza Marques, Aníbal Quijano, Edgardo Lander, Grosfoguel, Dussel e outros, os quais se afiliam à mesma linha de pensamento. Apesar de nem todos apresentarem a perspectiva da decolonialidade como objeto de estudo, os autores têm em comum o questionamento do colonialismo continuado na/da Amazônia.

Assim, buscamos, a partir deste trabalho, chamar a atenção de professores, notadamente aqueles que atuam no ensino de ciências, quanto ao potencial pedagógico da música "BelémPará-Brasil", relativo a diferentes domínios temáticos socioambientais na abordagem à Amazônia, sob a perspectiva decolonial, de modo, inclusive, a contribuir para o conhecimento histórico dos povos amazônidas. A música em questão constitui-se um agente mediador, auxiliando a construção de um diálogo com a realidade, permitindo a interpretação pessoal e abrindo, simultaneamente, espaço para a socialização e a construção de saberes (ZAMPRONHA, 2007).

Dessa forma, a análise detalhada da música "Belém-Pará-Brasil" desvela as diferentes formas de opressão e de dominação do colonialismo vinculados ao contexto amazônico. Além do mais, favorece o reconhecimento de nossa própria história, quando esta denuncia a

\footnotetext{
${ }^{1}$ Composta em 1980, por Edmar da Rocha, integrante da Banda Mosaico de Ravena e lançada em 1992.
} 
imposição de visão de mundo e hierarquias que nos subalternizam, o que evidencia seu potencial decolonial.

\title{
2 UMA BREVE ABORDAGEM AO COLONIALISMO E A COLONIALIDADE NA AMAZÔNIA
}

O termo colonialidade expressa a intenção de denunciar que o sistema de dominação colonial continua presente, mesmo com o fim das colônias. Os estudos sobre a colonialidade reúne um grupo de pesquisadores, chamado Modernidade/Colonialidade (M/C), que analisa os mecanismos e as ações que atuam para a manutenção do modelo hegemônico, nos seguintes termos:

[...] o M/C atualiza a tradição crítica de pensamento latino-americano, oferece releituras históricas e problematiza velhas e novas questões para o continente. Defende a 'opção decolonial' - epistêmica, teórica e política - para compreender e atuar no mundo, marcado pela permanência da colonialidade global nos diferentes níveis da vida pessoal e coletiva. (BALLESTRIN, 2013, p.13).

No âmbito do coletivo $\mathrm{M} / \mathrm{C}$, a expressão “decolonial” é utilizada pelos pesquisadores como referência às diversas abordagens teóricas que denunciam os mecanismos de dominação e de opressão como resultados da histórica dominação colonial (BALLESTRIN, 2013). Por sua vez, na Amazônia, a dominação colonial é reconhecida e deixou (e ainda tem deixado) marcas. $\mathrm{Na}$ atualidade, além das potências coloniais Espanha, Portugal, Inglaterra, França, Bélgica, Holanda e Itália (ZALAMENA, 2018), outros países constituem impérios coloniais que se assemelham às potências coloniais citadas, assim temos:

\begin{abstract}
Actualmente, as zonas centrais da economia-mundo capitalista coincidem com sociedades predominantemente brancas/europeias/euro-americanas, tais como a Europa Ocidental, o Canadá, a Austrália e os Estados Unidos, enquanto as zonas periféricas coincidem com povos não-europeus outrora colonizados. O Japão é a única excepção que confirma a regra, na medida em que nunca foi colonizado nem dominado pelos europeus e, à semelhança do Ocidente, desempenhou um papel activo na construção do seu próprio império colonial. A China, embora nunca colonizada na sua totalidade, viu-se periferizada pelo uso de entrepostos coloniais como Hong Kong e Macau, e por intervenções militares directas (GROSFOGUEL, 2008, p. 127).
\end{abstract}

Porto-Gonçalves (2015, p. 77) chama atenção para que “[...] não nos esqueçamos de que na Amazônia cinco potências coloniais deixaram suas marcas: Portugal, Espanha, França, Holanda e Inglaterra. Portanto, há uma tradição de presença dessas grandes potências coloniais na região". O modelo agroexportador, com a extração dos recursos naturais, visibiliza a presença das potências coloniais na Amazônia (PORTO-GONÇALVES, 2015).

O conceito de colonialidade, por se tratar de uma estrutura complexa, entrelaçada, não cabe só no âmbito do poder, sendo estendida para outros campos. Assim, a “[...] colonialidade se reproduz numa tripla dimensão: do poder, do saber e do ser (BALLESTRIN, 2013, p.100). 
Neste trabalho, discutiremos a colonialidade do poder por considerar que este conceito possui maior abrangência ao tratarmos os demais. A colonialidade do poder abrange em si diversas vertentes, a saber: controle da economia, controle da autoridade, controle da natureza e dos recursos naturais, controle do gênero e da sexualidade e controle da subjetividade e do conhecimento (BALLESTRIN, 2013).

O pesquisador Anibal Quijano elaborou o conceito de colonialidade do poder, que expressa a dominação colonial desde que espanhóis e portugueses chegaram e subjugaram a América Latina, nos seguintes termos:

Esta idea y la clasificación social en ella fundada (o "racista"), fueron originadas hace 500 años junto con América, Europa y el capitalismo. Son la más profunda y perdurable expresión de la dominación colonial, y fueron impuestas sobre toda la población del planeta en el curso de la expansión del colonialismo europeo. Desde entonces, en el actual patrón mundial de poder impregnan todas y cada una de las áreas de existencia social y constituyen la más profunda y eficaz forma de dominación social, material e intersubjetiva, y son, por eso mismo, la base intersubjetiva más universal de dominación política dentro del actual patrón de poder (QUIJANO, 2000, p. 1).

Segundo Quijano (2000), a colonialidade do poder evidencia-se dentro de cada formação social, na hierarquização de pessoas, conforme características culturais e econômicas, apontando o sistema de dominação como sendo uma relação histórica de exploração, fruto das relações capitalistas. De acordo com Grosfoguel (2008, p. 126), “[...] continuamos a viver sob a mesma matriz de poder colonial [...] os povos não-europeus continuam a viver sob a rude exploração e dominação européia/euro-americana". Nesse ponto, cabe esclarecer que

Dizer colonialidade não é o mesmo que dizer colonialismo. Não se trata de uma forma
decorrente nem antecedente da modernidade. Colonialidade e modernidade
constituem duas faces de uma mesma moeda. Da mesma maneira que a revolução
industrial europeia foi possível graças às formas coercivas de trabalho na periferia, as
novas identidades, direitos, leis e instituições da modernidade, de que são exemplo os
Estados-nação, a cidadania e a democracia, formaram-se durante um processo de
interacção colonial, e também de dominação/exploração, com povos não-ocidentais
(GROSFOGUEL, 2008, p.126). O fato é que o fim da administração das colônias não rompeu com a estrutura políticoeconômica do poder das nações coloniais. Embora as nações colonizadas tenham se organizado politicamente em Estados independentes, persistem as estruturas de dominação. A compreensão dessa reorganização do sistema-mundo implica distinguir colonialidade de colonialismo, de modo que

A colonialidade permite-nos compreender a continuidade das formas coloniais de dominação após o fim das administrações coloniais, produzidas pelas culturas coloniais e pelas estruturas do sistema-mundo capitalista moderno/colonial. A expressão 'colonialidade do poder' designa um processo fundamental de estruturação do sistema-mundo moderno/colonial, que articula os lugares periféricos da divisão 
internacional do trabalho com a hierarquia étnico-racial global e com a inscrição de migrantes do Terceiro Mundo na hierarquia étnico-racial das cidades metropolitanas globais. Os Estados-nação periféricos e os povos não-europeus vivem hoje sob o regime da "colonialidade global" imposto pelos Estados Unidos, através do Fundo Monetário Internacional (FMI), do Banco Mundial (BM), do Pentágono e da OTAN. As zonas periféricas mantêm-se numa situação colonial, ainda que já não estejam sujeitas a uma administração colonial (GROSFOGUEL, 2008, p.126).

Desse modo, a globalização na modernidade permitiu a ampliação das formas de dominação. O processo de estruturação do sistema-mundo capitalista moderno/colonial não se reduz apenas às nações europeias, inclui também outras nações hegemônicas, com destaque para os Estados Unidos. Essa dinâmica, que subalterniza as nações periféricas, insere-se no regime de colonialidade global. As formas de dominação pressupõem que as "[...] estratégias ideológico-simbólicas globais e a cultura colonial/racista, juntamente com os processos de acumulação capitalista e o sistema interestatal, são constitutivas das relações centro/periferia à escala mundial" (GROSFOGUEL, 2008, p.128). As relações de poder envolvem ideologias racistas para justificarem a dominação dos países centrais. Em termos gerais,

Desde o início da formação do sistema-mundo capitalista, a acumulação incessante de capital esteve sempre enredada com ideologias racistas, homofóbicas e sexistas. A expansão colonial europeia foi conduzida por homens europeus heterossexuais. Aonde quer que chegassem, traziam consigo os seus preconceitos culturais e formavam estruturas heterárquicas de desigualdade sexual, de género, de classe e raciais. Deste modo, no "capitalismo histórico" - entendido como "sistema heterárquico" ou "estrutura heterogénea" - o processo de incorporação periférica na acumulação incessante de capital foi sendo constituído por, e enredado com, hierarquias e discursos homofóbicos, sexistas e racistas (GROSFOGUEL, 2008, p.128).

Considerando os aspectos acima arrolados, a modernidade é uma construção eurocêntrica que pensa o mundo e a humanidade tendo como referência a Europa. A modernidade é "[...] um dispositivo de conhecimento colonial e imperial em que se articula essa totalidade de povos, tempo e espaço como parte da organização colonial/imperial do mundo" (LANDER, 2005, 13). Para além desse conhecimento totalizador, há outras formas de ser, outras formas de organização do conhecimento.

Dussel (2005, p. 28), ao se referir à modernidade, caracteriza-a como "[...] uma emancipação, uma 'saída' da imaturidade por um esforço da razão como processo crítico, que proporciona à humanidade um novo desenvolvimento do ser humano. Esse processo ocorreria na Europa, essencialmente no século XVIII". No entendimento de Dussel (2005), é preciso a superação da modernidade, mediante negação do mito da modernidade, mostrando a "outraface", a história das vítimas, dos atos irracionais de violência do ocidente dominador. Essa negação se dá com o "descobrir" a face ocultada da modernidade: a opressão do escravo, do 
negro, do índio, da mulher. Em razão disso, a modernidade passa de "vítima inocente" para responsável pela violência irracional implementada no seu processo de conquista original (LANDER, 2005). Assim,

\begin{abstract}
A sociedade ocidental tem transformado a diferença em hierarquia: a diferença que a natureza produziu em branco e preto foi transformada em racismo, em um processo que coloca um como superior e o outro como inferior. A diferença homem/mulher se transformou em machismo, hierarquizando-se enquanto uma superioridade do homem sobre a mulher. E assim se deu com os povos, hierarquizando-os como se houvesse uma linearidade que iria dos povos mais simples até os mais complexos, que seria a civilização industrial européia (PORTO-GONÇALVES, 2015, p.85).
\end{abstract}

Dessa forma, estabeleceram-se relações desiguais entre pessoas e grupos na repartição do poder, com base, principalmente, nos critérios de raça e gênero.

\title{
3 Metodologia
}

A pesquisa configurou-se como de natureza qualitativa (MINAYO, 2016) e, na apreciação do conteúdo da música "Belém-Pará-Brasil", recorremos à análise de conteúdo, do tipo categorial temática (BARDIN, 2009). A “[...] análise de conteúdo é uma análise dos significados podendo também ser dos significantes" (BARDIN, 2009, p. 37). A análise de conteúdo compreende três fases: pré-análise, exploração do material e tratamento dos resultados. A análise do tipo categorial temática visa a busca pelo tema a partir dos "núcleos de sentidos" obtidos com a organização das unidades de registro e sua posterior categorização (BARDIN, 2009).

A pré-análise, também chamada de leitura flutuante, se caracteriza pela leitura exaustiva do material, de modo a ser impregnado pelo conteúdo, o que nos levou à leitura cuidadosa da letra da música "Belém-Pará-Brasil”, fazendo marcações de palavras e frases, na identificação das unidades de registro, que consiste no "[...] tratamento descritivo identificando as unidades de codificação, ou as de registro (BARDIN, 2009, p. 37, destaque do autor). Essas, por sua vez, podem ser uma palavra ou mesmo frase que compreenda uma significação.

Em seguida, na exploração do material, fizemos a organização das unidades de registro, identificando os temas de forma a alcançar a compreensão de toda a canção. Nessa etapa, passamos à interpretação, levando em conta o conteúdo da mensagem expressa em cada verso e estrofe da música "Belém-Pará-Brasil”, de forma a compreender o sentido da comunicação.

Para o tratamento do material, faz-se inferências e interpretações, tendo em vista um quadro teórico (BARDIN, 2009). Desse modo, buscou-se uma visão lógica sequencial das unidades de registro no seu sentido explícito. A interpretação da letra da música "Belém-ParáBrasil" teve a lente teórica da colonialidade, que resultou na elaboração de três categorias de 
análise: (1) ocupação da Amazônia, invisibilidade dos amazônidas e o discurso desenvolvimentista, (2) estereótipos criados sobre a Amazônia e os amazônidas e (3) influência das culturas alienígenas na Amazônia. Desse modo, de forma sequencial, as estrofes da música foram apresentadas e discutidas ao longo do texto, conforme categorias de análise correspondentes, segundo perspectivas decoloniais.

\section{Resultados}

Nesta seção apresentamos as categorias resultantes da análise temática na apreciação do conteúdo da música "Belém-Pará-Brasil", segundo perspectivas decoloniais, nas seções que se seguem.

\subsection{OCUPAÇÃO DA AMAZÔNIA, INVISIBILIDADE DOS AMAZÔNIDAS E O DISCURSO DESENVOLVIMENTISTA}

A música "Belém-Pará-Brasil”, da Banda Mosaico de Ravena, expressa o lamento e, ao mesmo tempo, um protesto diante de um contexto histórico que causou sofrimento aos habitantes da região, colocando-os na condição de excluídos. Vários momentos foram evidenciados, dentre os quais destacamos a integração das rodovias, que atraiu indústrias e outros tipos de investimentos para a região e que acarretou consequências no modo de vida da população local.

A música, na estrofe que se apresenta abaixo, retrata a chegada de povos de diferentes regiões do Brasil na região Norte, com o intuito de explorar as riquezas desta região, capitaneada pelo Estado. A ocupação é justificada pelo progresso e desenvolvimento. O resultado danoso do movimento de ocupação da Amazônia gerou pobreza e desigualdade social como consequência da exploração desmedida.

$$
\begin{aligned}
& \text { Região Norte, ferida aberta pelo } \\
& \text { progresso, sugada pelos sulistas e } \\
& \text { amputada pela consciência nacional... }
\end{aligned}
$$

De fato, ao considerar a perspectiva histórica, as regiões Sul e Nordeste do país, na década de 1970, passavam por tensões sociais devido aos conflitos agrários nestas regiões. Com isso, a implementação do Plano de Integração Nacional (PIN) resolveu dois problemas considerados de segurança nacional: a "[...] ocupação da Amazônia e a minimização dos conflitos por terra nas regiões Sul e Nordeste" (SOUZA, 2010, p. 205).

O governo militar, além das preocupações com segurança, tinha outros dois grandes motivos para justificar a ocupação da Amazônia brasileira, a saber: 
a) a necessidade premente de deslocar parcela da população da Região Nordeste, uma vez que a seca e o solo desgastado, somados à concentração de terras em latifúndios, criavam um grande número de trabalhadores sem-terra, passíveis de serem cooptados pela ideologia "comunista"; b) os conflitos de terra na Região Sul, decorrentes da mecanização da agricultura e do aumento dos latifúndios, restringiam o acesso a terra e, assim como no Nordeste, provocavam enorme tensão social (SOUZA, 2010, p. 203).

A ocupação da Amazônia situa-se entre o "[...] moderno e o atrasado da concepção burguesa de desenvolvimento linear, de crescimento e de acúmulo ao acaso do capitalismo" (MARQUES, 2019, p. 12). Esse processo faz parte da ordem colonial de saque que se insere no contexto do sistema-mundo, criando uma relação de subordinação entre os países periféricos e os países centrais (GROSFOGUEL, 2008).

A ocupação da Amazônia foi um projeto arquitetado pelo Estado Nacional em conjunto com a expansão capitalista, com a justificativa de necessidade de ocupação e de desenvolvimento da região. Assim,

Sob a ditadura do Estado Brasileiro, abriram-se as fronteiras da Amazônia ao capital, com a imagem de estar sendo realizado a reforma agrária, via assentamentos agropecuários aos povos marginalizados e despossuídos do país. Foi através da transferência dessas massas que passaram essa visão, quando na verdade a maioria dos atores que migraram foram “oxigenar" os grandes projetos econômicos, por meio de sua força de trabalho, e se tornaram proletários por meio da ordem sistêmica imposta na região (PICOLI, 2006, p.37-38).

A ocupação da Amazônia fez parte das diretrizes sistêmicas mundiais. Os grupos econômicos que se instalaram na região tinham por finalidade acumular riquezas, no contexto de um projeto de superexploração da força de trabalho dos marginalizados e dos despossuídos, possibilitando atingir tal intento.

O discurso que justifica as políticas de desenvolvimento para a Amazônia tenta trazer a ideia de necessidade deste desenvolvimento para a região. Essa estratégia trata de uma falácia que mascara uma necessidade de sobrevivência do sistema-mundo e não o contrário. Assim, a “[...] inversão é exemplar, como se a Amazônia dependesse do sistema-mundo (da produção de mercadorias) do que este dela, e isto não procede" (MARQUES, 2019, p. 15).

Por sua vez, as classes sociais que viabilizaram esse projeto assim se caracterizavam:

[...] uma representada por grupos econômicos que ali vão expandir seus negócios para reproduzir capitais; a outra formada por marginalizados e despossuídos no processo histórico com sucessivas migrações ao longo de suas gerações, que fazem parte do exército industrial de reserva do país (PICOLI, 2006, p. 7).

Apesar do discurso do Estado Brasileiro de promover a assistência ao caboclo da região e resolver o problema da fome do Nordeste, bem como os problemas sociais do Sul do país, o que houve, na realidade, foi a elaboração de um projeto para beneficiar as grandes empresas 
nacionais e estrangeiras, internacionalizando a Amazônia com a expansão dos grandes conglomerados capitalistas (PICOLI, 2006).

A integração do Norte ao Sul do país facilitou a exploração e o saqueamento da região amazônica. A abertura das rodovias que ligam o Norte ao Sul do país foram as feridas abertas pelo progresso. Essas feridas, as rodovias, não apenas integraram as diferentes regiões, mas facilitaram a expropriação das nossas riquezas. Desse modo,

As estradas federais serviram de propaganda para o governo atrair empresas e pessoas para a região, bem como sinônimo de estrutura. Figuram-se como os corredores mais importantes as rodovias Cuiabá-Santarém, Cuiabá-Porto Velho, Belém-Brasília e Transamazônica. Estes são exemplos de integração proporcionados pelo Estado para a abertura desta vasta região. Além dos esforços do governo militar para contribuir para o já avançado processo de destruição, países centrais com interesse capitalista foram oportunos e decisivos no tocante a devastação e ao enxugamento das riquezas naturais da região (PICOLI, 2006, p. 49).

A construção de rodovias provocou grandes alterações na configuração geoespacial da região amazônica. As rodovias foram construídas no formato de espinhas de peixe. A abertura das vias principais levou à construção de outras estradas vicinais, inclusive de "chão batido". Assim, as rodovias "rasgaram" a floresta, favorecendo a formação de cidades com o desenvolvimento das atividades madeireira e pecuarista, causando grandes custos socioambientais (MARQUES, 2019).

Outra questão em destaque na letra da música é o descaso da sociedade brasileira em relação à Amazônia e com o seu povo. É como se "[...] o Sul e o Sudeste reproduzissem para a região o olhar de quem vê o Brasil a partir do "primeiro mundo". Esse descaso com a região é atribuído às políticas governamentais, incluindo as educacionais, quando se questiona: "Qual o espaço que se destina à região nos livros didáticos de história? Já passou a hora de olharmos esse imenso território como algo somente exótico e estranho" (MARQUES, 2019, p. 33-34).

Nesse sentido, Porto-Gonçalves (2018, p. 36) nos diz que “[...] precisamos superar o 'colonialismo interno' que ignora as múltiplas nacionalidades/povos/etnias que habitam o mesmo território dos diferentes estados/sociedades que se veem a si mesmos/as como uninacionais $[\ldots] "$ ". Esse colonialismo interno tem sido devastador para os grupos/classes em situação de subalternização. A superação da colonialidade significa reivindicar o reconhecimento da diferença e lutar contra as diversas formas de opressão e de exploração que subalternizam os amazônidas.

Na Amazônia, atualmente, a mineração permanece intensa e, desta forma, assistimos no “[...] novo século a entrada e generalização de inúmeras empresas minerais explorando produtos 
diversos no território amazônico" (MARQUES, 2019, p. 210), conteúdo trazido na estrofe que se segue:

Porque ninguém nos leva a sério?

Só o nosso minério...

Assim,

Com o apoio estatal, mantidos no governo do novo século, ampliou-se a pilhagem de riquezas minerais, sociais e bioenergéticas. Grandes mineradoras multinacionais estão em diversos pontos da região, particularmente em sua porção oriental. É ocaso do Pará, mas isso ocorre em toda a região [...] (MARQUES, 2019, p. 214).

Historicamente, a região amazônica foi marcada pela exploração dos recursos naturais, e a visão de Amazônia como "vazio demográfico" autoriza a ocupação por não amazônidas. Assim, na medida em que estaria vazia e esvaziada de gente, a Amazônia é natureza, vista com fonte inesgotável de recursos, passível de exploração (PORTO-GONÇALVES, 2019).

Sobre o discurso de progresso, de desenvolvimento, Marques (2019, p. 220) pergunta: “Desenvolvimento para quem?”. Esse questionamento se faz necessário, uma vez que

As políticas estatais tomaram o progresso como decorrência do capital, romper com o seu 'atraso', integrá-la ao restante do país (e ao imperialismo). Aos setores oprimidos não coube perguntar qual o sentido do progresso que lhes interessava. [...]. O Estado colocou o público a serviço do privado em detrimento do social. A ocupação da região foi efetivada pela pata do boi, escavadeira da mineração e equipamentos do agronegócio, gerando uma massa de despossuídos (MARQUES, 2019, p. 279).

Os povos amazônicos não são levados a sério. Ainda hoje persiste um processo histórico que minimiza a nossa importância no cenário nacional, aprofunda desigualdades sociais e aumenta o número de despossuídos e de miseráveis. É preciso reverter esse processo histórico e, assim,

Não podemos naturalizar a miséria, achar normal pessoas passando fome em meio à abundância dos outros. Não podemos deixar de ver as injustiças (e tomar posição pelos injustiçados) sob pena de sermos coniventes com os opressores. Não podemos tornar invisíveis pessoas marginalizadas pelo 'desenvolvimento' capitalista. Por isso, diante das proposições desenvolvimentistas, devemos sempre perguntar: qual desenvolvimento? Para onde? Para quem? (MARQUES, 2019, p. 282).

É preciso nos inquietarmos, denunciando essas práticas de subalternização. Por meio da educação, por exemplo, poderemos construir novas formas de relações com a natureza, que considere a necessidade dos povos da Amazônia e, deste modo, construir um projeto de desenvolvimento humano para a região, que valorize a sociobiodiversidade, a vida.

\subsection{ESTEREÓTIPOS CRIADOS SOBRE A AMAZÔNIA E OS AMAZÔNIDAS}

O cinema retrata a visão do estrangeiro sobre a Amazônia. Isso é resultado de construções discursivas sobre a Amazônia por pessoas que não conhecem a região. Assim, a 
região passou a fazer parte do imaginário nacional e estrangeiro como isolada e subdesenvolvida; por sua vez, essas construções refletem também nas visões sobre os povos que aqui vivem como sendo pessoas bárbaras, ligadas à selva (BELO, 2013).

A letra da música "Belém, Pará, Brasil" traz um tom irônico sobre a visão que se tem da Amazônia e dos amazônidas. Com isso, Edmar da Rocha mostra, na estrofe que se segue, o preconceito das pessoas de outras regiões do país com a região, por associar os amazônidas a uma vida silvícola, sem nenhum estado de civilização:

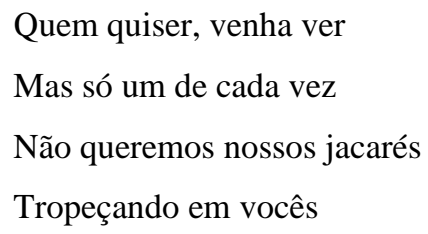

A pesquisa de Belo (2013), ao investigar a visão do estrangeiro sobre a Amazônia, a partir da análise de vários filmes que retratam a região Amazônica, mostrou que são visões míticas, de figuras excêntricas e bárbaras, que reforçam estigmas sobre a Amazônia e seu povo. Esses estigmas fazem com que as pessoas acreditem que a região é uma floresta inteira, e que todos que moram aqui são índios, que andamos nus, que sobrevivemos da pesca, que moramos em oca, que andamos de canoa e usamos arco e flecha.

O povo da região sofre com a xenofobia, pois nos tratam como não civilizados, como se aqui só tivessem índios, animais e floresta. A invenção do arcaico e do bárbaro foi uma construção do império colonial para justificar a imposição da necessidade de progresso, tendo a civilização ocidental como referência. A libertação dos índios da barbárie fazia parte da missão colonial, que consistia em transformar os indígenas em seres mais evoluídos (MENESES, 2010).

No cinema, a “[...] leitura cristalizada do espaço e dos costumes amazônicos limita abordagem interpretativas mais apuradas, principalmente dos estrangeiros, sobre as relações humanas nesse espaço" (BELO, 2013, p. 103-104). Com isso, constrói-se uma imagem exótica, que convém ao europeu pensar quem são os indígenas e os povos da Amazônia, resultando na apreensão deformada dos amazônidas.

As narrativas sobre a Amazônia reafirmam as construções dos viajantes sobre os índios como "[...] mosaico de mistérios e estranheza, carrega o emblema da terra sem lei" (BELO, 2013, p. 114), o que nos remete aos diversos relatos sobre os povos indígenas brasileiros, especialmente os tupinambás, que colaboraram para aumentar o preconceito, associando as práticas de antropofagia dos tupinambás a atos animalescos bestiais. Assim, 


\begin{abstract}
Acrescente-se que, por constituir-se numa retaliação mútua e ritual, a vingança tupinambá $[\ldots]$ adquire contornos estabelecidos pela distinção natureza/cultura. Isso diferencia a antropofagia tupinambá de uma simples reação instintiva, de natureza puramente animal. A natureza social inerente à vingança torna-se a fronteira para a concepção da antropofagia como uma instituição cultural (LIMA, 2017, p. 201).
\end{abstract}

As narrativas de viajantes e missionários contribuíram para a construção de discursos civilizatórios, o que é denunciado, em parte, na estrofe que se segue:

\author{
A culpa é da mentalidade \\ Criada sobre a região \\ Por que é que tanta gente teme? \\ Norte não é com M
}

A intenção de ironizar essa mentalidade sobre os índios da Amazônia é também expressa nos versos “nossos índios não comem ninguém/agora é só hamburguer”. Em realidade, o ritual de antropofagia era a demonstração de bravura dos índios Tupinambás e não uma expressão da violência animalesca. Essas narrativas construídas por pessoas que desconheciam tais práticas serviram para atribuir aos indígenas reações de repugnância e os qualificar de criaturas bestiais. No trecho “agora é só hamburguer” também tem a intenção de mostrar a influência de outras culturas. Essa questão será discutida na seção seguinte.

Os estereótipos criados sobre os povos da Amazônia reportam aos primórdios da colonização. Essas falsas imagens, criadas por pessoas que não conhecem a região, visam hierarquizar e marginalizar nosso povo, para, com isso, reafirmar a superioridade dos brancos, grupo dominante da sociedade; tentando, de certo modo, nos destituir da nossa identidade. É o que nos parece, ao refletir sobre a estrofe abaixo:

\title{
Deformados até a alma \\ Sem cultura e opinião \\ O nortista só queria \\ Fazer parte da nação
}

Assim, o discurso colonizador, com base na ideia de diferença, procura colocar os brancos como civilizados, portadores do progresso e os demais como inferiores, por isso atrasados, preguiçosos e indolentes, excluídos do projeto maior de Estado.

\subsection{INFLUÊNCIA DAS CULTURAS ALIENÍGENAS NA AMAZÔNIA}

A canção traz elementos que evidenciam a influência da cultura norte-americana tanto no Brasil quanto na Amazônia. O termo alienígena se refere às tentativas de se nacionalizar uma cultura estrangeira com o apagamento da nossa etnicidade. Nessa perspectiva, a cultura 
alienígena nos impõe a um estranhamento, por esta não se identificar com a nossa realidade e, por isso, alienígena (SEYFERTH, 1997).

Na música "Belém, Pará, Brasil", essa influência é evidenciada na nossa alimentação, gostos musicais, vestimentas e outros que passamos a supervalorizar em substituição aos costumes locais/regionais - cultura alienígena. Nos versos já destacados anteriormente, “Nossos índios não comem ninguém/agora é só hamburguer”, observa-se a conotação irônica quanto às práticas antropofágicas dos tupinambás, como visto anteriormente.

Por sua vez, o autor da música enfatiza o consumo de hamburguer como um alimento que já faz parte da alimentação dos povos da Amazônia. Alimento este, que é originalmente norte-americano. Essa influência se impõe de forma ideológica, disseminando o ideal de classe dominante. Assim,

\begin{abstract}
A cultura norte-americana se impôs de forma ideológica na sociedade brasileira, não havendo muitas possibilidades de negação dos traços culturais que estavam se estabelecendo. Assim como no período contemporâneo, no começo da inserção dos produtos culturais norte-americanos no Brasil, os meios de comunicação eram os fatores fundamentais para disseminação do ideal da classe dominante (POLON, 2016, p. 42).
\end{abstract}

A influência da cultura norte-americana é evidência do processo de transculturação, que, segundo Ianni (2000), é a própria “ocidentalização do mundo"; e, no caso do Brasil, os Estados Unidos criaram aqui a ideia de "Europa". Assim a transculturação, que é uma consequência da globalização, disseminou o american way of life no Brasil.

$\mathrm{O}$ american way of life simbolizava toda ordem de modernidade e de progresso. No Brasil, o capital norte-americano encontrou o estímulo necessário e se impôs como modelo de modernidade. Apesar das desigualdades socioeconômicas, os brasileiros foram estimulados a se adequarem aos padrões dos países desenvolvidos. No entanto, apenas uma pequena elite conseguiria se adequar aos padrões estabelecidos (POLON, 2016).

A música mostra que a globalização facilitou a imposição da nova cultura. A forma como os Estados Unidos influenciaram a cultura de outras nações, substituindo os costumes locais/regionais pelos costumes específicos da cultura norte-americana é conhecido como americanização. Por isso, Edmar da Rocha, por meio da Música “Belém-Pará-Brasil”, pede que devolvam a nossa cultura, importante na constituição da identidade amazônica.

\footnotetext{
Ah! Chega de malfeitura

Ah! Chega de tristes rimas

Devolvam a nossa cultura

Queremos o Norte lá em cima
} 


\author{
Porque, onde já se viu? \\ Isso é Belém \\ Isso é Pará \\ Isso é Brasil
}

A canção traz que o nortista está cansado da exploração e que queremos que a nossa identidade/cultura seja valorizada, como mostra a estrofe acima. Dentre as estrelas que representam os estados, na bandeira do Brasil, o Pará tem destaque no alto. Isso porque foi o último estado a ser criado, não por outra razão, e é assim que queremos ser vistos, valorizados como um povo que faz parte do Brasil. Que a nossa cultura seja respeitada, não com a mentalidade atrasada que insistem em nos imputar, mas como um povo que faz parte da história do Brasil e que faz parte do país também.

Novamente a canção evoca, na estrofe que se segue, a influência dos Estados Unidos na nossa cultura, ao mesmo tempo em que censura a substituição de produtos locais/regionais por aqueles alheios à nossa cultura alimentar; acrescentamos, cuja qualidade nutricional é, no mínimo, questionável.

$$
\begin{aligned}
& \text { Aqui a gente toma guaraná } \\
& \text { quando não tem Coca-Cola } \\
& \text { Chega das coisas da terra } \\
& \text { que o que é bom, vem lá de fora }
\end{aligned}
$$

Nos versos acima há um clamor/súplica para a valorização da nossa cultura, da nossa identidade cultural. O Brasil tem, em suas regiões, diversidades gastronômicas, folclóricas, musicais e outras. Na região Norte temos o açaí, o tacacá, o tucupi, o tecnobrega e o carimbó que são típicos da região. Essa é a identidade cultural que precisamos resguardar. Quando desejamos a cultura do invasor, perdemos nossas próprias raízes. Nesse contexto,

\begin{abstract}
A cultura material e imaterial norte-americana se mostra presente no cotidiano do povo brasileiro, tanto que a língua inglesa até pouco tempo era a única lecionada nas escolas públicas de ensino básico como língua estrangeira moderna, cedendo hoje espaço também para a língua espanhola e outras, variando conforme a região do país. Portanto, palavras estrangeiras estão inseridas no vocabulário dos sujeitos e, em muitos casos eles nem percebem isso. Os filmes e músicas em inglês são amplamente difundidos nas mídias brasileiras [...] (POLON, 2016, p. 40).
\end{abstract}

Por sua vez, a música "Belém-Pará-Brasil", na estrofe abaixo apresentada, remete a transformações das paisagens urbanas, principalmente pela verticalização das construções e substituição das construções coloniais por faixadas mais modernas e ampliações das mesmas.

\footnotetext{
Vão destruir o Ver-o-Peso

e construir um shopping center
} 


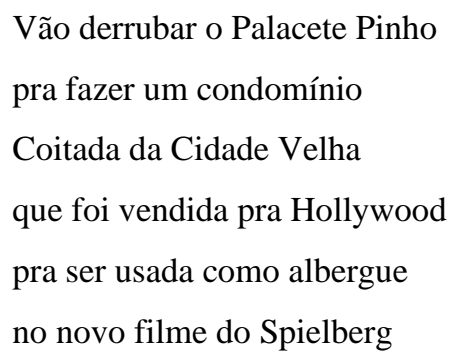

Nesse trecho, percebemos a crítica ao implantar o modelo das cidades americanas que possuem inúmeros shoppings, condomínios etc. O Palacete Pinho e a Cidade Velha fazem parte dos processos históricos vividos na Amazônia, numa linha de continuidade que se inicia com sua condição de colônia e perdura até os tempos atuais. O Mercado do Ver-o-Peso tem um destaque especial na música por sua importância, pois este é a maior feira a céu aberto da América Latina, um dos mais antigos mercados do Brasil, datado do século 17.

A destruição do nosso patrimônio histórico é uma forma de continuar o processo de colonização, apagando nossa memória por meio da desvalorização da nossa cultura, de forma a nos inferiorizar e retirar o nosso direito sobre o espaço. Aqui vemos a crítica diante da modernidade, que insiste com a ideia que o "progresso" é sempre vantajoso, mesmo que venha a influenciar a cultura local de forma negativa.

Percebemos, nesse trecho da música, a ideia de transformar elementos que fazem parte da cultura e da identidade do local, em "algo moderno", como se natural fosse. O fato é que nosso patrimônio cultural está sendo substituído por elementos da cultura norte-americana. A essência dos amazônidas está na sua cultura. Assim, o desenvolvimento da região implica considerar a cultura regional/local, em relação com a natureza.

\section{CONSIDERAÇÕES FINAIS}

A análise da música "Belém-Pará-Brasil" sob a perspectiva decolonial possibilitou reflexões sobre questões sociais e ambientais que desvelam a presença da ordem colonial de saque e de exploração, ainda presente sob diferentes matizes. Esse processo analítico nos levou a outras narrativas sobre a Amazônia, para além do que está posto na história oficial. Assim, a interpretação e a atribuição de sentido à letra da música "Belém-Pará-Brasil”", em conjunto com as leituras sobre colonialidade e decolonização, nos permitiu perceber as dinâmicas da modernidade histórica, da formação social capitalista com sua performance e mutações, que em solo amazônico ainda hoje mantém os interesses hegemônicos capitalistas.

Ademais, com a perspectiva de análise aqui adotada, buscamos oferecer uma leitura própria da região amazônica, com destaque ao estado do Pará, tendo como materialidade 
mediadora a música Belém-Pará-Brasil, de modo a nos situarmos neste cenário, principalmente como subordinados, posição que nos delega o sistema-mundo capitalista moderno-colonial; e, a partir disto, nos posicionarmos criticamente sobre este estado de coisas, e assumir uma postura insurgente, como caminho plausível para a descolonização, libertação e autonomia da sociedade amazônica, até aqui na condição subalternizada.

No mesmo sentido, criar novas oportunidades ao fazer docente é um desafio que se impõe. Assim, as reflexões desenvolvidas neste ensaio buscaram chamar atenção para as "marcas" da colonialidade presentes na música Belém-Pará-Brasil. Tratá-las na sala de aula, decerto, contribui para uma educação decolonial, importante para a humanização e a emancipação dos sujeitos oprimidos frente ao sistema-mundo capitalista moderno-colonial. Acreditamos que a leitura da música pela ótica epistemológico decolonial contribui para a construção de uma outra racionalidade, cuja perspectiva funda-se no reconhecimento das diferenças, das identidades e das subjetividades; de modo a resistir, insurgir-se, frente às hegemonias impingidas pelos paradigmas europeu e norte-americano.

\section{REFERÊNCIAS}

BALLESTRIN, Luciana. América Latina e o giro decolonial. Revista Brasileira Ciências Políticas, Brasília, n. 11, p. 89-117. 2013.

BARDIN, Laurence. Análise de conteúdo. Lisboa: Edições 70, 2009.

BELO, Geovane Silva. O olhar estrangeiro estigmatizado(r) do cinema: invenção, sustentação e reinvenção do imaginário sobre a Amazônia. 154 f. Dissertação. Programa de Pós-Graduação em Artes. Universidade Federal do Pará. 2013.

DUSSEL, Enrique. Europa, Modernidade e Eurocentrismo. In: LANDER, Edgardo (Org.). A colonialidade do saber: eurocentrismo e ciências sociais. Perspectivas Latino-Americanas. Buenos Aires: CLACSO, Consejo Latinoamericano de Ciencias Sociales, 2005. p. 25-34.

GROSFOGUEL, Ramón. Para descolonizar os estudos de economia política e os estudos póscoloniais: Transmodernidade, pensamento de fronteira e colonialidade global. Revista Crítica de Ciências Sociais, Coimbra, v. 1, n. 80, p. 115-147, 2008.

IANNI, Octavio. Enigmas da modernidade-mundo. Rio de Janeiro: Civilização Brasileira, 2000 .

LANDER, Edgardo. Ciências sociais: saberes coloniais e eurocêntricos. In: LANDER, Edgardo (Org). A colonialidade do saber: eurocentrismo e ciências sociais. Perspectivas Latino-Americanas. Buenos Aires: CLACSO, Consejo Latinoamericano de Ciencias Sociales, 2005. p.7-24. 
LEFF, Enrique. Saber Ambiental: sustentabilidade, racionalidade, complexidade, poder. 6 ed. Petrópolis, RJ: Vozes, 2008.

LIMA, Jarbas Couto. A translucidez da antropofagia Tupinambá. Espaço Ameríndio, Porto Alegre, v. 11, n. 1, p. 195-218, 2017.

MARQUES, Gilberto de Souza. Amazônia: riqueza, degradação e saque. 1 ed. São Paulo: Expressão Popular, 2019.

MENESES, Maria Paula. O "indígena" africano e o colono "europeu”: a construção da diferença por processos legais. E-cadernos CES, Coimbra, n. 7, p. 68-93, 2010.

OLIVEIRA, Andreici Marcela Araújo de. Povos indígenas, desenvolvimento e colonialismo na Amazônia brasileira. In: CASTRO, Edna; PINTO, Renan Freitas (Org.). Decolonialidade e sociologia na América Latina. Belém: NAEA; UFPA, 2018. p. 355-386.

PEIXOTO, Rodrigo; FIGUEIREDO, Kércia. Colonialidade do poder: conceito e situações e decolonialidade no contexto atual. In: CASTRO, Edna; PINTO, Renan Freitas (Org.).

Decolonialidade e sociologia na América Latina. Belém: NAEA; UFPA, 2018. p. 127-158.

PICOLO, Fiorelo. O capital e a devastação da Amazônia. $1^{a}$ edição. São Paulo: Expressão Popular, 2006.

POLON, Luana Caroline Künast. Tênues fronteiras: inserção da cultura norte-americana nas práticas de consumo dos brasileiros. Revista Perspectiva Geográfica, Marechal Cândido Rondon, v. 11, n. 14, p. 38-47, 2016.

PORTO-GONÇALVES, Carlos Walter. Amazônia, Amazônias. São Paulo: Contexto, 2019.

PORTO-GONÇALVES, Carlos Walter. Amazônia enquanto acumulação desigual de tempos: uma contribuição para a ecologia política da região. Revista Crítica de Ciências Sociais, Coimbra, v. 107, p. 63-90, 2015.

PORTO-GONÇALVES, Carlos Walter. Encruzilhada Civilizatória. Tensões territoriais em curso. Bolívia: IPDRS/CIDES - UMSA, 2018.

QUIJANO, Aníbal. Colonialidad del poder, globalización y democracia. Sociedad y Política Ediciones. Lima, Perú, 2000. Disponível em:

https://www.rrojasdatabank.info/pfpc/quijan02.pdf. Acesso em: 10 de jun. 2020.

SANTOS, Milton. A natureza do espaço. Técnica e tempo. Razão emoção. São Paulo: HUCITEC, 2002.

SEYFERTH, Giralda. A assimilação dos imigrantes como questão nacional. Mana. Estudos de Antropologia Social, Rio de Janeiro, v. 3, n. 1, p. 95-131. 1997.

SOUZA, Marcela Tockler Coelho. Cultura invisível: conhecimento indígena e patrimônio imaterial. Anuário Antropológico, Brasília, n. 1, p. 149-174, 2010.

SOUZA, Nádia Simas. A Amazônia brasileira: processo de ocupação e a devastação da floresta. Boletim Científico ESMPU, Brasília, v. 9, n. 32/33, p. 199-235, 2010. 
VIEIRA, Ima Célia Guimarães; TOLEDO, Peter Mann de; HIGUSHI, Horácio. A Amazônia no Antropoceno. Ciência e Cultura, Campinas/São Paulo, v. 70, n. 1, p. 56-59, 2018.

ZALAMENA, Juliana Costa Meinerz. Colonização e qualidade democrática: apontamentos com base no democracy index. Revista Eletrônica de Ciência Política, Paraná, v. 9, n. 1, p. 70-93, 2018.

ZAMPRONHA, Maria de Lourdes Sekeff. Da música e seus recursos. 2. Ed. São Paulo: Editora UNESP, 2007.

Recebido em: 1 de julho de 2020.

Aprovado em: 23 de dezembro de 2020. 